\title{
DIREITO HUMANO AO DESENVOLVIMENTO
}

\section{HUMAN RIGHT TO DEVELOPMENT}

\author{
${ }^{1}$ João Carlos Campanilli \\ ${ }^{2}$ Samyra Haydêe Dal Farra Naspolini Sanches
}

\section{RESUMO}

O tema escolhido para o presente artigo se deu em razão da importância que o desenvolvimento assumiu, tendo em vista a evolução social marcada pelo progresso da humanidade e que está sendo objeto de reflexão em diversas áreas. Objetiva-se com o presente tema verificar se os o desenvolvimento é um direito humano, uma faculdade ou se é fruto da natureza do ser humano, analisando-se, para tanto, as noções de direitos humanos, sociedade, desenvolvimento, além da legislação e doutrina. Para isso, será adotado o método hipotético dedutivo, confrontando as hipóteses para se chegar a uma eventual conclusão acerca da questão.

Palavras-chave: Desenvolvimento; Direito Humano; Faculdade; Evolução.

\begin{abstract}
The theme chosen for the present article was due to the importance that the development assumed, in view of the social evolution marked by the progress of the humanity and that is being object of reflection in diverse areas. The purpose of this theme is to verify whether development is a human right, a faculty or if it is the fruit of the nature of the human being, analyzing, for that, the notions of human rights, society, development, besides the legislation and doctrine. For this, the hypothetical deductive method will be adopted, confronting the hypotheses to arrive at a possible conclusion about the question.
\end{abstract}

Keywords: Development; Human Right; Choice; Evolution.

\footnotetext{
${ }^{1}$ Mestrando em Direito pela Universidade Nove de Julho - UNINOVE, São Paulo (Brasil).

E-mail: jccampanilli@ hotmail.com

${ }^{2}$ Doutora em Direito pela Pontifícia Universidade Católica - PUC, São Paulo (Brasil). Professora Pesquisadora pela Universidade Nove de Julho - UNINOVE, São Paulo (Brasil). E-mail: samyranaspolini@gmail.com
} 


\section{INTRODUÇÃO}

Propõem-se, no presente artigo, discorrer sobre o Direito Humano ao Desenvolvimento, tendo em vista as discussões que cercam a questão na atualidade, por conta da globalização e dos avanços tecnológicos que afetam a sociedade.

Questiona-se na pesquisa se o desenvolvimento é um Direito Humano, uma faculdade ou se decorreu da evolução natural do ser humano na sociedade.

Para isso, será feita a análise do desenvolvimento humano dentro do contexto social histórico, com o objetivo de se entender como se deu o desenvolvimento humano na sociedade, bem como para colher elementos a fim de dirimir tais indagações, oportunidade em que será adotado o método hipotético dedutivo, combinado com método auxiliar histórico de pesquisa, confrontando, para tanto, as variáveis do direito humano ao desenvolvimento, dentro da doutrina e na legislação.

\section{O que é um direito humano?}

Em sua época, Kant já asseverava que todo ser humano existe como um fim em si mesmo por sua própria natureza e que todo homem tem dignidade e não preço como as coisas.

No entanto, acerca da questão, não busca o presente artigo desenvolver o conceito do que é direito humano, pois não é esse o objetivo do presente trabalho, mas agregar noções capazes de desenvolver o raciocínio acerca do tema de fundo.

Nesse sentido, explica Eros Grau (2015, p. 130), que

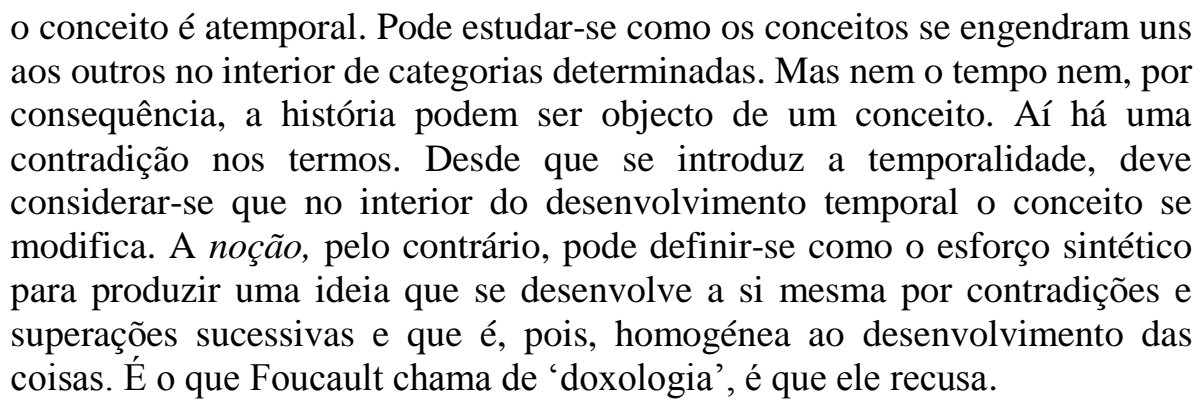

Entretanto, os direitos humanos, no plural, estão estabelecidos Declaração Universal dos Direitos Humanos, proclamada pela Assembleia Geral das Nações Unidas em Paris, em 10 de Dezembro de 1948, através da Resolução 217 A (III) da Assembleia Geral, estabelecendo, pela primeira vez, a proteção universal dos direitos humanos. 
Já Vladmir Oliveira da Silveira e Maria Mendez Rocasolano (2010, p. 216), entendem que

\begin{abstract}
os direitos humanos são uma realidade complexa de natureza ética, jurídica e política e que para melhor compreensão do âmbito relativo à fundamentação desses direitos, é possível fixar a seguinte classificação: (i) fundamentação ético-jurídica; (ii) fundamentação jurídico-positiva; e (iii) fundamentação jurídico-política, considerando também a importância de se retornar, no momento histórico atual, a reflexão sobre o fundamento ou a razão de ser dos direitos humanos, porém, fazem referência a definição trazida por Paces-Barba, para quem os direitos humanos são faculdades que o direito atribui a pessoas e aos grupos sociais, expressão de suas necessidades relativas à vida, liberdade, igualdade, participação política ou social, ou a qualquer outro aspecto fundamental que afete o desenvolvimento integral dos indivíduos em uma comunidade de homens livres, exigindo o respeito ou a atuação dos demais homens, dos grupos sociais e do Estado, com garantia dos poderes públicos para restabelecer seu exercício em caso de violação ou para realizar prestação.
\end{abstract}

Todavia, importante anotar que a etimologia Direitos Humanos vem sendo classificada como Direitos Humanos Fundamentais, na qualidade de gênero, sendo as espécies os Direitos Humanos e os Direitos Fundamentais. A espécie Direitos Humanos está inserida num contexto Internacional ou Regional, estabelecidos por organismos internacionais, por meio de tratados, pactos e declarações, os quais os Estados passam a ratificar dentro do seu ordenamento jurídico doméstico.

Ademais, hodiernamente, os Direitos Humanos estão ligados ao conceito de Estado Cooperação, em que os organismos internacionais passam a cooperar com o Estado signatário de tratados internacionais de Direitos Humanos, submetendo-se, a tribunais e cortes internacionais.

Os Direitos Fundamentais, ao contrário dos Direitos Humanos, refere-se à previsão legal de tais direitos dentro do ordenamento jurídico nacional ou doméstico, por intermédio de suas Constituições.

De notar que muito embora o Estado faça sua adesão à eventual Tratado Internacional de Direitos Humanos, este não perde sua soberania, mas, tão somente, se submete a regras de conduta estabelecidas em tais ajustes.

Da análise efetuada, pode-se depreender que não há um conceito definido na doutrina para Direito Humano, pois se configura uma abordagem aberta à interpretação, dependendo do momento histórico, político e econômico, a qual a sociedade está afetada, além das peculiaridades que os cidadãos estão vinculados, dentro do respectivo Estado-nação. 


\section{O Desenvolvimento é um direito humano?}

Para discorrer acerca da questão indaga-se: O Desenvolvimento é um Direito Humano? É uma faculdade humana ou decorre da evolução natural do ser humano em sociedade? Para responder a tais indagações será necessário fazer um breve retorno, a fim de se aferir como se originou a sociedade e a evolução do homem dentro dela.

Segundo Dalmo de Abreu Dallari (1995, p.46), as sociedades surgiram da base familiar, que tinha em seu núcleo o chefe como referência, dotado de poder para tomada de decisões e administração do patrimônio, sendo que cada família primitiva se ampliou e deu origem a um Estado.

Sócrates, em seus diálogos, registrado por Platão (2007, p. 66-67), dispôs que "um Estado nasce das necessidades dos homens; ninguém basta a si mesmo, por isso, um homem se junta a outro por uma necessidade e mais outro por outra necessidade porque têm muitas delas. Assim, muitas pessoas se reúnem num mesmo local para se valerem mutuamente e também para ter companhia", o que evidencia, assim, desde o período axial a busca do desenvolvimento e o progresso da vida em sociedade.

Continua Dallari, citando Robert Lowie (1995, p. 47), que o Estado é um germe em todas as sociedades humanas, as quais dispensa dele enquanto se mantêm simples e pouco desenvolvidas, mas aquelas sociedades que atingem maior grau de desenvolvimento têm absoluta necessidade do Estado, e então ele se constitui.

No entanto, a doutrina de Dallari (1995, p. 47), destaca algumas posições acerca origem da sociedade, senão vejamos:

a) para muitos autores, o Estado, assim como a própria sociedade sempre existiu, pois sempre que o homem vive sobre a terra acha-se integrado numa organização social, dotada de poder e com autoridade para determinar o comportamento de todo o grupo;

b) uma segunda ordem de autores admite que a sociedade humana existiu sem o Estado durante um certo período, mas depois foi constituído para atender às necessidades ou às conveniências dos grupos sociais;

c) a terceira posição é a dos autores que só admitem como Estado a sociedade política dotada de certas características muito bem definidas. Assim, na doutrina de Dallari, citando Karl Schmidt (1995, p. 44) “o Estado não é um conceito geral válido para todos os tempos, mas é um conceito histórico concreto, que surge quando nasce a ideia e a prática da soberania, o que só ocorreu no século XVII". 
Registre-se, também, a referência feita a Baballadore Pallieri (1995, p. 44-45), que indica com precisão o nascimento do Estado, anotando que a "data oficial em que o mundo ocidental se apresenta organizado em Estados é a de 1648, ano em que foi assinada a paz de Westfália”.

Não é demais destacar, ainda, a posição entre naturalistas e contratualistas, sendo que os primeiros defendem a posição de que o Estado se formou de modo espontâneo, sem a convergência das vontades dos indivíduos. Sustenta-se a existência de uma sociedade natural, isto é, há uma exigência da própria natureza do homem, que o induz a viver agregadamente junto a seus semelhantes.

Os contratualistas defendem a posição de que o Estado se formou mediante a concretização da vontade de diversos homens e de que o homem vive em sociedade por vontade própria, isto é, mediante um ato consciente de vontade similar a um contrato.

Já num contexto mais atual, Balmes Vega Garcia (2008, p. 15), citando Manuel Castells, em "A Sociedade em Rede", assevera que "as sociedades são organizadas em processos estruturados por relações historicamente determinadas de produção, experiência e poder".

Feitas tais considerações acerca da sociedade e Estado, vislumbra-se que o desenvolvimento humano se deu pela melhoria da técnica relacionada a sobrevivência, conforme anotado por Sócrates, na República de Platão.

Neste contexto, verifica-se que a evolução humana, desde os períodos mais remotos, já remete a um desenvolvimento, propriamente dito, como foi bem destacado com a geração do fogo, a criação da pólvora, de ferramentas e armas, entre outros atualmente conhecidos e que estão por vir, destacando-se, para tanto, que, durante os séculos XVI a XVIII, foram concretizados diversos avanços das técnicas, principalmente na área têxtil, com a criação do tear ${ }^{3}$, posteriormente para setor da metalurgia, com o advento eletricidade e da máquina a vapor ${ }^{4}$.

\footnotetext{
${ }^{3}$ Segundo Balmes Vega Garcia (2008, p. 45), o tear só se afirmará definitivamente em 1830, na Inglaterra e mais tarde no continente. Ao longo dos anos seguintes todas essas invenções são aperfeiçoadas, completadas, e estendidas a outros setores (...) A mula e o tear são automatizados, aumentando sua capacidade de produção por volta da metade do século XX, enquanto o trabalhador, cada vez mais passivo, vigia várias máquinas ao mesmo tempo, com os mesmos gestos: a divisão e automatização do trabalho se aceleram.

${ }^{4}$ Acerca da questão, prossegue Balmes Vega Garcia (2008, p. 46) ressaltando a importância da invenção da máquina a vapor para a viabilização dos grandes empreendimentos econômicos, assim como observando como a técnica e a tecnologia consolidam-se apoiadas mais e mais na ciência, asseverando que foi, portanto, no século XVIII, na Inglaterra, que o progresso decisivo ocorreu Mas era ainda necessário aperfeiçoar um instrumento novo que fornecesse energia à novas invenções ou seja: a máquina a vapor que rapidamente se torna o símbolo da nova
} 
Com isso, tomando emprestado o termo de Vladimir Oliveira da Silveira (2010, p. 185), pode-se anotar que o processo dinamogênico do desenvolvimento, decorre da evolução temporal, fruto das conquistas e dos conhecimentos humanos, chegando aos dias atuais em que ganharam destaques no campo da engenharia genética, medicina, aeroespacial, entre outros.

Tanto é que Noberto Bobbio (2004, p. 210), considera o patrimônio genético como os direitos de quarta geração, além daqueles considerados de primeira geração, a liberdade, de segunda geração a igualdade e de terceira geração a solidariedade e fraternidade, só para fins de registro.

Importante consignar que com a ruptura do modelo absolutista houve a instalação do liberalismo, instituído pelas Revoluções Americana, em 1776, e Francesa em 1789, porém com ideologias diferentes, procurando a primeira se libertar dos laços coloniais da monarquia britânica e a segunda promovida pela classe burguesa em relação ao poder soberano, que praticava constantes abusos, surgindo-se, assim, o chamado direito de primeira geração ou dimensão ${ }^{5}$, ou Estado de Direito, caracterizado pela liberdade individual e de propriedade.

Com a concretização do direito à liberdade, o que se viu foi a abstenção do Estado nas relações privadas, o que proporcionou a produção em massa bens, mercadorias e serviço, sem respeitar qualquer tipo de direito humano, visando, tão somente, o lucro por parte da classe burguesa, a quem detinha o poder de produção, substituindo-se, assim, a figura do súdito e soberano para proprietário e subalterno.

Considerando o cenário precário instalado, durante no início do século $\mathrm{XX}$, houve um movimento para conter os abusos cometidos contra a classe operária, surgindo-se daí a necessidade de nova intervenção do Estado, mas desta vez para garantir igualdade de direitos em reação àqueles menos favorecidos, num contexto de desenvolvimento econômico, social e cultural.

era técnica. Pela rapidez da rotação, sua rentabilidade, sua alimentação simples à água e a carvão, a máquina de Watt pode ser fácil e utilmente adaptada a todas as 'máquinas' da indústria têxtil ou da metalurgia . As primeiras servem para o bombeamento das minas, mas a partir de 1785 passam a acionar as fiações de algodão, os laminadores, os martelos das forjas, os foles e os moinhos. Em 1870, as máquinas a vapor efetuam na Inglaterra um trabalho que antes exigiria 40 milhões de homens. As máquinas da indústria têxtil ou das metalurgias, as máquinas a vapor, e todas as grandes invenções, às vezes empíricas, retomadas e modificadas por pesquisadores modestos e que têm dificuldades em obter capitais necessários para seu trabalho, são inglesas e asseguram à Inglaterra uma grande supremacia técnica no início do século XIX. Antes mesmo de ter expirado o prazo de sua patente, em 1800, Boulton e Watt tinha construído cerca de 500 máquinas a vapor das quais somente algumas poucas haviam sido exportadas e instaladas no exterior. A primeira vaga de renovação técnica provém das pacientes pesquisas de artesãos convertidos em técnicos imaginosos.

${ }_{5}^{5}$ Alguns autores preferem utilizar o termo dimensões de direito em vez de gerações, pois este último passa a ideia de um direito prevalecer sobre aquele anterior. 
Esse período é marcado pela publicação das Constituições de 1917 no México ${ }^{6}$ e 1919 na Alemanha, que passou a garantir os direitos de férias, salários e aposentadoria em favor daqueles que trabalhavam na produção de bens e serviços, oportunidade em que se implementou os direitos de segunda geração, conhecido, também, como Estado do Bem Estar Social ou "Welfare State" ou Estado Social de Direito, voltado à coletividade.

Com o passar do tempo o mundo testemunhou, tristemente, a eclosão da Segunda Guerra Mundial, onde ocorreram diversas atrocidades em relação à dignidade humana, chegando-se ao ponto, inclusive, de se especular a possiblidade do fim do mundo, por conta do poder bélico de alguns países.

Diante de tais acontecimentos, o mundo se viu novamente obrigado a disciplinar a conduta humana. Entra em cena, dessa vez, os Direitos Humanos, por meio da elaboração da Carta das Nações Unidades de 1945, vinculada, posteriormente, pela Declaração Universal dos Direitos Humanos de 1948 e pelos dois Pactos Internacionais de 1966: O Pacto Internacional sobre Direitos Civis e Políticos e o Pacto Internacional sobre Direitos Econômicos, Sociais e Culturais.

Assim, verifica-se que, dentro do processo dinamogênico ${ }^{7}$, o Estado passou de absolutista para liberal - num aspecto da individualidade -, caracterizado pelo Estado de Direito, deste para social - num aspecto coletivo -, caracterizado pelo Estado Social de Direito e deste para solidário e fraterno, dentro de um Estado Social e Democrático de Direitos - num aspecto difuso e indeterminado -, configurando-se dentro deste processo a funcionalização dos direitos, visando a integração da liberdade, igualdade e solidariedade/fraternidade, sem excluir um em detrimento do outro, pelo contrário todos se complementado.

\footnotetext{
${ }^{6}$ A Constituição Mexicana de 1917 estava voltada a igualdade indígena.

7 Vladmir Oliveira da Silveira "por meio de um modelo geométrico-axiológico, a dinamogenesis explica o processo que fundamenta o nascimento e desenvolvimento de novos direitos no decorrer da história[...]. Com a intenção de garantir os direitos humanos a partir da interpretação dos valores tomaremos o paradigma da chamada dinamogenesis, cujo caminho se inicia com a observação sociológica - a qual entende que a sociedade é um "laboratório humano que dá os instrumentos e a matéria-prima para as construções jurídicas dos povos. Em geral entende-se que o direito se apoia e fundamenta na sociologia e na filosofia, pois a norma deve expressar valores e interesses que correspondam aos valores e interesses da sociedade em dado momento histórico. Por sua vez, ao manifestar a característica da reciprocidade, os valores atuam como elemento integrativo A dinamogenesis dos valores e o direito referem-se ao processo continuado no qual os valores estão imersos e que pode resumir-se nas seguintes etapas, que serão detalhadas adiante: 1) conhecimento-descobrimento dos valores pela sociedade; 2) posterior adesão social aos valores e a consequência imediata; e 3) concretização dos valores por intermédio do direito em sua produção normativa e institucional."
} 


\section{Das hipóteses para as indagações}

Dessa forma, levando-se em consideração o conteúdo exposto, quanto ao questionamento acerca se o Desenvolvimento é um Direito Humano, uma faculdade humana ou decorrente evolução da natureza humana, busca-se no ordenamento jurídico, bem como na doutrina as devidas explicações.

De notar que a questão ganhou evidência quando foi objeto de deliberação no âmbito da Organização das Nações Unidas, que culminou com a edição da Resolução 41-128, de 04 de dezembro de 1986, tendo como principal premissa a colocação do desenvolvimento como direito humano, conforme disposto em seu artigo $1^{\circ}$, senão vejamos:

\section{Artigo $1 .^{\circ} \mathrm{O}$ direito ao desenvolvimento é um direito humano inalienável em virtude do qual todos os seres humanos e todos os povos têm o direito de participar, de contribuir e de gozar o desenvolvimento econômico, social, cultural e político, no qual todos os direitos humanos e liberdades fundamentais se possam plenamente realizar.}

Importante destacar, também, que âmbito das Nações Unidas, em 1965, foi criado o Programa das Nações Unidas para o Desenvolvimento - PNUD, sendo a agência líder da rede global de desenvolvimento da ONU, trabalhando, principalmente, com o combate à pobreza, bem como com o desenvolvimento humano em nível mundial.

De notar que o PNUD está presente em 166 países do mundo, colaborando com governos, a iniciativa privada e com a sociedade civil para ajudar as pessoas a construírem uma vida mais digna e em todas as suas atividades, encoraja a proteção dos direitos humanos e a igualdade de gênero e raça. Em 1990, o PNUD introduziu universalmente o conceito de Desenvolvimento Humano, que parte do pressuposto de que para aferir o avanço na qualidade de vida de uma população é preciso ir além do viés puramente econômico e considerar três dimensões básicas: renda, saúde e educação. Esse conceito consiste na base do Índice de Desenvolvimento Humano (IDH) e do Relatório de Desenvolvimento Humano (RDH), publicado anualmente pelo PNUD, sendo que, desde 2000, o Programa também fomenta o comprometimento e a discussão em prol do alcance dos Objetivos de Desenvolvimento do Milênio (ODM).

Por outro lado, valendo-se da doutrina, Bobbio (2004, p. 5), em sua "A era dos direitos", que retrata bem a questão do direito humano ao desenvolvimento, quando, em sua introdução, dispõe que "os direitos do homem, por mais fundamentais que sejam, são direitos históricos, ou seja, nascidos em certas circunstâncias, caracterizadas por lutas em defesa de novas liberdades contra velhos poderes, e nascidos de modo gradual, não todos de uma vez nem 
de uma vez por todas" e que, segundo o jurista (2004, p. 9), “os novos carecimentos nascem em função da mudança das condições sociais e quando o desenvolvimento técnico permite satisfazê-los, o que culmina com novas gerações de direitos, destacando, por exemplo, os direitos de $3^{\mathrm{a}}$ e $4^{\mathrm{a}}$ gerações, que estão em fase de consolidação, ao contrário dos direitos de primeira e segunda geração que se concretizaram no ordenamento jurídico".

Dentro dessa noção de Direito Humano ao Desenvolvimento, Bobbio (2004, p. 32-33) faz a seguinte afirmação: "Sabemos hoje que também os direitos ditos humanos são o produto não da natureza, mas da civilização humana; enquanto direitos históricos, eles são mutáveis, ou seja, suscetíveis de transformação e de ampliação. Basta examinar os escritos dos primeiros jusnaturalistas para ver quanto se ampliou a lista dos direitos", fazendo, também, a seguinte reflexão:

\begin{abstract}
A quem pretenda fazer um exame despreconceituoso do desenvolvimento dos direitos humanos depois da Segunda Guerra Mundial, aconselharia este salutar exercício: ler a Declaração Universal e depois olha em torno de si. Será obrigado a reconhecer que, apesar das antecipações iluminadas dos filósofos, das corajosas formulações dos juristas, dos esforços dos políticos de boa vontade, o caminho a percorrer é ainda longo. E ele terá a impressão de que a história humana, embora velha de milênios, quando comparada às enormes tarefas que estão diante de nós, talvez tenha apenas começado.
\end{abstract}

Para Bobbio (2004, p.52), o conjunto de esforços que o homem faz para transformar o mundo que o circunda e torná-lo menos hostil, pertencem tanto as técnicas produtoras de instrumentos, que se voltam para a transformação do mundo material, quanto as regras de conduta, que se voltam para modificação das relações interindividuais, no sentido de tornar possível uma convivência pacífica e a própria sobrevivência do grupo e que os instrumentos e regras de conduta forma um mundo da "cultura", contraposto ao da "natureza".

De notar que o pensamento do autor evidencia a importância da positivação das condutas do homem na transformação da sociedade, em contra ponto aos defensores do jusnaturalismo, para fins de garantia do desenvolvimento harmônico da sociedade, salientou Bobbio (2004, p. 52) que,

encontrando-se num mundo hostil, tanto em face da natureza quanto em relação a seus semelhantes, o homem buscou reagir a essa dupla hostilidade inventando técnicas de sobrevivência com relação à primeira, e de defesa com relação à segunda, sendo estas últimas representadas pelos sistemas de regras que reduzem os impulsos agressivos mediante penas, ou estimulam os impulsos de colaboração e de solidariedade através de prêmios.

Assim, dentro do raciocínio criado, a partir da concepção de Bobbio afere-se que o desenvolvimento é um Direito Humano, fruto da evolução social, que merece ser tutelado, tanto 
pelo ordenamento jurídico doméstico, quanto pelas organizações internacionais, por meio de suas Declarações, Assembleias e Relatórios.

Neste sentido, afirmam Samyra Haydêe Dal Farra Naspolini Sanches e Vladmir Oliveira da Silveira (2013, p. 117), que, na análise da função sócio-solidária da empresa privada e o desenvolvimento sustentável

\begin{abstract}
o direito ao desenvolvimento apresenta-se como a dimensão atual, por excelência, dos direitos humanos econômicos, que a partir da segunda metade do século XX, podem ser definidos como um conjunto de valores consagrados em instrumentos jurídicos internacionais e/ou nacionais, "destinados a fazer respeitar e concretizar as condições de vida que possibilitem a todo ser humano manter e desenvolver suas qualidades peculiares de inteligência, dignidade e consciência e permitir a satisfação de suas necessidades materiais e espirituais.
\end{abstract}

Registram, ainda, os referidos autores (2013, p. 117), que "o direito ao desenvolvimento, como desdobramento dos direitos humanos econômicos, apresentam-se numa prerrogativa inerente à natureza humana, atuando na esfera particular de cada cidadão e perante as sociedades como um todo, surgindo daí a necessidade de o Estado elaborar e consagrar políticas públicas voltadas para a sua concretização”.

Já Balmes Vega Garcia (2008, p. 11-12), reconhece a Técnica como traço que caracteriza o ser humano, admitindo que a mesma pode se constituir um instrumento para o desenvolvimento, ou seja, o direito ao desenvolvimento é parte integrante da constelação dos direitos humanos, entendendo, assim, que a pesquisa científica e a capacitação tecnológica podem ser instrumentos para promover o desenvolvimento, o que se justifica o status constitucional da ciência, tecnologia e inovação, previsto no Título II - Dos Direitos e Garantias Fundamentais da Constituição Federal de 1988. Assim, sob o ponto de vista do citado autor, o desenvolvimento configura-se como um direito humano.

Considerando a pesquisa em torno do tema, não poderia deixar de fazer menção a "Modernidade Líquida" de Bauman que, acerca do desenvolvimento humano em sociedade, discorre sobre a substituição da modernidade pesada pela modernidade leve, em razão da atual conjuntura, impulsionada pela globalização.

A substituição, descrita por Baumam, recai nas grandes máquinas, que ocupam maiores espaços, pelo sistema "nano", ou seja, do "hardware" para o "software", anotando, inclusive, que "quanto menor melhor para se administrar", além de que derretimento dos sólidos e a diminuição do espaço e do tempo como forma de favorecer o progresso social.

Para Bauman (2001, p. 20-21), as sociedades ausentes de avanços são consideradas sólidas, pesadas e lentas, pois dentro dessa modernidade líquida, fruto do desenvolvimento 
humano, decorrente do capitalismo predominante no mundo, o engajamento ativo na vida das populações subordinadas não é mais necessário (ao contrário é fortemente evitado como desnecessariamente custoso e ineficaz) - e, portanto, o "maior" não só não é mais o "melhor", mas carece de significado racional e que agora é o menor, mais leve e mais portátil que significa melhoria e "progresso".

Todavia, tal progresso recai na escolha do homem, independente de previsão normativa, quando Bauman (2001, p. 40-42) discorre que

\begin{abstract}
nós humanos, nos encontramos "por nossa própria conta" - o que significa que, desde então, não conhecemos mais limites ao aperfeiçoamento além das limitações de nossos próprios dons herdados e adquiridos, de nossos recursos, coragem e vontade e determinação. E que o homem faz o homem pode desfazer, além de que o colapso gradual e o rápido declínio da antiga ilusão moderna, bem como a desregulamentação e a privação das tarefas e deveres modernizantes são características da nossa forma de modernidade nova e diferente, além de que essa importante alteração se reflete na realocação do discurso ético/político do quadro da "sociedade justa" para o dos "direitos humanos", isto é, voltando o foco daquele discurso ao direito de os indivíduos permanecerem diferentes e de escolherem à vontade seus próprios modelos de felicidade e de modo de vida adequado.
\end{abstract}

Acerca da faculdade do desenvolvimento pelo indivíduo em sociedade, Bauman (2001, p. 42) faz a seguinte passagem:

\begin{abstract}
Não olhe para trás, ou para cima; olhe para dentro de você mesmo, onde supostamente residem todas as ferramentas necessárias ao aperfeiçoamento da vida - sua astúcia, vontade e poder", registrando, ainda, o seguinte: "não mais grandes líderes para lhe dizer o que fazer e para aliviá-lo da responsabilidade pela consequência de seus atos; no mundo dos indivíduos há apenas outros indivíduos cujo exemplo seguir na condução das tarefas da própria vida, assumindo toda a responsabilidade pelas consequências de ter investido a confiança nesse e não em qualquer outro exemplo.
\end{abstract}

Bauman (2001, p. 52) afirma que a "individualização chegou para ficar; toda elaboração sobre os meios de enfrentar seu impacto sobre o modo como levamos nossas vidas deve partir do reconhecimento desse fato".

Já Serge Latouche, em seu "Pequeno Tratamento do Decrescimento Sereno" (2009, p. 42), já é mais radical, pregando o rompimento com o modelo capitalista num ideal de desenvolvimento sustentável, utilizando-se do circulo virtuoso dos oito "erres", quais sejam: reavaliar, reconceituar, reestruturar, redistribuir, relocalizar, reduzir, reutilizar e reciclar.

Ao contrário de Bauman, destaca Latouche (2009, p. 128-129) tratar-se não só de diminuir a velocidade da acumulação, mas também de questionar o conceito para inverter o processo destrutivo, registrando, ainda, o seguinte: "nossa concepção da sociedade do decrescimento não é nem um impossível retorno para trás nem um acomodamento ao capitalismo. É uma "superação" (se possível, uma boa ordem) da modernidade. "É tão impossível convencer o capitalismo a limitar o crescimento quanto é impossível persuadir um 
ser humano a parar de respirar", escreveu Murray Boochin. O decrescimento é forçosamente contra o capitalismo".

Dentre as relevantes passagens descritas por Latouche (2009, p. 8-9), chamou a atenção quando o autor registra que "o desenvolvimento é uma palavra atóxica, qualquer que seja o adjetivo com que o vistam", fazendo, para tanto, o seguinte registro

\begin{abstract}
Até um economista tão convencional como Cláudio Napoleoni escreveu no fim de sua vida: "Já não podemos nos contentar com imaginar um 'novo modelo de desenvolvimento'. A expressão 'novo modelo de desenvolvimento' carece de sentido. Caso se queira encontrar um novo modelo, já não será um modelo de desenvolvimento [...]. Não creio que se possa resolver simultaneamente o problema de um crescimento mais forte e de uma mudança qualitativa do desenvolvimento.
\end{abstract}

Não obstante, o citado autor faz alusão ao relatório do WWF (2009, p, 8), relativo ao ano de 2006, que somente um país preenche os critérios do desenvolvimento sustentável, quais sejam, um patamar de desenvolvimento humano elevado e uma pegada ecológica sustentável: Cuba.

Ignacy Sachs afirma de qualquer forma, o desenvolvimento não pode ser visto em separado do crescimento econômico, sendo que só o crescimento econômico não garante o desenvolvimento. Assim, o mau desenvolvimento pode ser encontrado quando se verifica somente o crescimento do Produto Interno Bruto (PIB) acompanhado do aumento do desemprego, pobreza e desigualdades sociais, como acontece em países em desenvolvimento (SACHS, 2008, p.71). Afirma, ainda, que o desenvolvimento é um conceito multidimensional e que contém uma perspectiva ambiental na medida em que explicita uma preocupação com as gerações futuras.

Os estudos sobre o desenvolvimento sustentável que vieram posteriormente foram no sentido de limitação do desenvolvimento econômico na sociedade de consumo globalizada, com a afirmação de um desenvolvimento sustentável que se dá em três dimensões: social, ambiental e econômica. Segundo Ignacy Sachs, em Prefácio à obra de José Eli Veiga, esta adjetivação do desenvolvimento como sustentável, deveria ser desdobrada em desenvolvimento: "socialmente includente, ambientalmente sustentável e economicamente sustentado no tempo." (grifos do autor) (VEIGA, 2008, p.10).

Parafraseando Bobbio (2004, p. VI), “detesto os fanáticos”, porém, se faz necessário aprender a respeitar as ideias dos outros, de compreender antes de discutir, de discutir antes de condenar, pois outras concepções merecem consideradas na presente exposição, até mesmo para chegar a uma conclusão acerca das indagações relativas ao direito humano ao desenvolvimento, 
além dos diversos debates que giram em torno da questão, devendo fazer uma ponderação dentro contexto social.

\section{CONCLUSÃO}

Dos estudos efetuados pode-se concluir que, de fato, o desenvolvimento é um direito humano, conforme estabelecido pela Declaração dos Direitos ao Desenvolvimento, publicada no âmbito da Organização das Nações Unidas, nascido de circunstância histórica, de modo gradual, não todos de uma vez, por conta do aprimoramento dos conhecimentos e das técnicas em face das hostilidades da natureza e de seus semelhantes, conforme bem anota Bobbio.

Todavia, muito embora o desenvolvimento seja considerado um Direito Humano, atualmente o tema é pauta de análise por diversos doutrinadores, em razão do desenvolvimento estar, de certa forma, ligado à liberdade, que foi se modificando e se ampliando, em função de inovações técnicas no campo da transmissão e difusão das ideias e das imagens e do possível abuso que se pode fazer dessas inovações, algo inconcebível quando o próprio uso não era possível ou era tecnicamente difícil.

Ademais, dentro do estudo realizado, pôde-se aferir que a temática Direitos Humanos ao Desenvolvimento configura-se, também, uma escolha do homem na sociedade moderna, considerando os novos contornos que a matéria vem ganhando, em razão das noções pósmodernidade, modernização da modernidade, segunda modernidade ou modernidade fluída, que, segundo Bauman, preconiza a emancipação do homem na sociedade, dentro da ideia de individualização.

Concernente às variáveis que admitem o desenvolvimento como Direito Humano, há aqueles consideram tal premissa um direito natural do homem, tendo em vista que está intrínseco na natureza humana, em razão da busca pela melhoria na qualidade de vida, desde os primórdios da vida.

Compartilham do mesmo ideal, aqueles que admitem ser o desenvolvimento um direito humano, porém não sob a concepção de um direito natural, mas fruto da normatização desse direito na sociedade, ou seja, estabelecido pelo ordenamento jurídico internacional ou doméstico, como forma de regular as condutas nas sociedades, permitindo a criação das técnicas de sobrevivência e a defesa dessas em sociedade.

Há aqueles que, também, admitem o desenvolvimento como direito humano, todavia defendem uma mitigação da noção desse desenvolvimento, de forma sustentável, com vistas a 
garantia dos direitos das futuras gerações, estabelecido em decorrência das gerações ou dimensões de direitos, conforme citado.

Já outros, defendem que, muito embora o desenvolvimento esteja positivado, trata-se de uma faculdade do homem em optar ou não pelo progresso, levando-se em consideração a realidade social na qual estão inseridos, chegando-se ao ponto de se propor rupturas com modelos adotados, para o fim de garantir a melhor qualidade de vida e preservação mundial em toda sua espécie.

Contudo, cumpre destacar que o Direito Humano ao desenvolvimento depende da condição econômica de cada País, independente do regime econômico adotado, seja capitalista ou socialista, sendo certo que para aqueles que adotaram o sistema capitalista haverá uma tendência maior ao desenvolvimento, tendo em vista o regime de competição instalado, por outro lado, para aqueles que adotaram um sistema socialista, o direito ao desenvolvimento humano tenderá a ser menor, pois se busca a igualdade aos membros que integram essa sociedade.

Ademais, depreende-se que a discussão em torno dos Direitos Humanos ao desenvolvimento configura-se um debate constante, considerando que a sociedade está em permanente evolução, motivo pelo qual o presente artigo mostra-se apenas o início de uma jornada para futuras análises e reflexões.

\section{REFERÊNCIAS}

BAUMAN, Zygmunt. Modernidade Líquida. Tradução Plínio Dentzien. Rio de Janeiro: Ed. Zahar. 2001.

BENACCHIO, Marcelo; PARREIRA, Liziane. Da Análise Econômica do Direito para a Análise Jurídica da Economia: a concretização da sustentabilidade. Revista Prisma Jurídico. São Paulo: UNINOVE. Vol 1. 2012.

BOBBIO, Norberto. A era dos Direitos. Tradução Carlos Nelson Coutinho; apresentação de Celso Lafer. Nova ed. Rio de Janeiro. Ed. Elsevier. 2004.

BONAVIDES, Paulo. Curso de direito constitucional. 13. ed. São Paulo: Malheiros, 2003.

CANÇADO TRINDADE, Antônio Augusto. A proteção internacional dos direitos humanos e o Brasil (1948-1997): as primeiras cinco décadas. Brasília: Editora da Universidade de Brasília, 1998. 
O legado da declaração universal e o futuro da proteção internacional dos direitos humanos. In: AMARAL JÚNIOR, Alberto do; MOISÉS, Cláudia Perrone (Orgs.). O cinqüentenário da Declaração Universal dos Direitos do Homem. São Paulo: Edusp, 1999.

CANOTILHO, José Joaquim Gomes. Direito constitucional e teoria da Constituição. 3. ed. Coimbra: Coimbra Editora, 1998.

COMPARATO, Fábio Konder. A Afirmação Histórica dos Direitos Humanos. $7^{\mathrm{a}} \mathrm{ed}$. Ed. Saraiva. 2010.

DALLARI, Dalmo de Abreu. Elementos da Teoria Geral do Estado. 19ª Edição. São Paulo. Ed. Saraiva. 1995.

GARCIA, Balmes Vega. Direito e Tecnologia: Regime Jurídico da Ciência, Tecnologia e Inovação. São Paulo. Ed. LTR. 2008.

GRAU, Eros Roberto. A Ordem Econômica na Constituição de 1988. 17ª Ed. São Paulo. Malheiros. 2015.

IANNI, Octavio. A sociedade global. 5. ed. Rio de Janeiro: Civilização Brasileira, 1997.

KEYNES, John Maynard. O fim do laissez-faire. In:. SZMRECSÁNYI, Tamás (Org.). 2. ed. São Paulo: Ática, 1984. (Coleção Os Grandes Cientistas Sociais).

São Paulo: Atlas, 1988. Teoria geral do emprego, do juro e da moeda.

LATOUCHE, Serge. Pequeno Tratado do Decrescimento Sereno; Tradução Cláudia Berliner. São Paulo: Editora WMF Martins Fontes, 2009.

MAILLART, Adriana Silva; NASPOLINI SANCHES, Samyra Dal Farra. O Direito fundamental de acesso à justiça e suas implicações para o direito fundamental ao desenvolvimento. IN: BAEZ, Narciso Leandro Xavier; SILVA, Rogério Luiz Nery; SMORTO, Guido. Os desafios dos direitos humanos fundamentais na América Latina e na Europa. Joaçaba: Editora UNOESC, 2012. pp 581 - 600.

MEZZAROBA, Orides; MONTEIRO, Cláudia Servilha. Manual de metodologia da pesquisa no direito. $6^{\text {a }}$ ed. São Paulo. Ed. Saraiva. 2014.

ORGANIZAÇÃO DAS NAÇÕES UNIDAS. Programa das Nações Unidas para o desenvolvimento - PNUD. Disponível em: http://www.pnud.org.br. Acessado em 27.07.2016

PETTER, Lafayete Josué. Princípios constitucionais da ordem econômica: o significado e o alcance do art. 170 da Constituição Federal. São Paulo: Revista dos Tribunais, 2005.

PIOVESAN, Flavia. Direitos humanos e o direito constitucional internacional. São Paulo: Max Limonad. 1996. 
PLATÃO. A República. Obra completa. V. 4 e 5. $2^{\text {a }}$ ed. São Paulo. Ed. Escala. 2007.

SACHS, Ignacy. Desenvolvimento: includente, sustentável, sustentado. Rio de Janeiro: Garamond, 2008.

SARLET, Ingo Wolfgang A eficácia dos direitos fundamentais. 2. ed. Porto Alegre: Livraria do Advogado, 2001.

SILVEIRA, Vladmir Oliveira da; ROCASOLANO, Maria Mendez. Direitos Humanos. Conceitos, significados e funções. São Paulo. Ed. Saraiva. 2010.

SILVEIRA, Vladmir Oliveira da Silveira; MEZZAROBA, Orides; SANCHES, Samyra Haydêe El Farra Nasponili; COUTO, Mônica Bonetti. Empresa, funcionalização do Direito e Sustentabilidade: Função Sócio-Solidária da Empresa e Desenvolvimento. Justiça, Empresa e Sustentabilidade v.4. Curitiba. Ed. Clássica. 2013.

SCHUMPETER, Joseph A. Theorie der wirtsschaftlichen Entwicklung: eine unter suchung über Unternehmergewinn, Kapital, Kredit, Zins und den KonjunkturzyKlus. München: Verfaleg, 1998.

TELLES Júnior, Goffredo da Silva, O direito quântico. 5. ed. São Paulo: Max Limonad, 1980.

VEIGA, José Eli da. Desenvolvimento sustentável: o desafio do século XXI. Rio de Janeiro: Garamond, 2008, p. 10.

VIEIRA, Oscar Vilhena. Direitos humanos: normativa internacional. São Paulo: Max Limonad, 2001. 